\title{
Freud and Literature: between Science and Intuition
}

\author{
Dr. Tarek Musleh
}

Professor of English Literature at Jadara University, Jordan

\begin{abstract}
It is generally assumed that science is involved in the world of facts and material proof that is based on experimentation, whereas intuition, which largely depends on human impulse, doest not demand decisive evidence and is usually influenced by culture.
\end{abstract}

Freud has established psychoanalysis as a new science, and his theories have somewhat shaped modern thought. He has a scientific turn of mind but some of his conclusions were strained and perhaps influenced by his personal intuition and judgments. He presents a negative view of writers by drawing on their work and emphasizing their neurosis and escapism. He exaggerates the role of sex in our life, especially infantile sexuality and the Oedipus complex. He assumes the superiority of males through his theory of the penis envy. And possibly, influenced by the present conditions of life, he establishes the death wish as an integral part of human desire to return to oblivion.

Many of his followers broke away with him and established their own schools. They generally opposed Freud's generalizations and over-emphasis on sex and human ego-centrism; instead, they tried to present a positive view of writers and literature, and constructed a healthier view of individuals in society.

Owing largely to Freud, Psychoanalysis is now firmly established as a new science, although the individual intuition of psychologists still plays a part, simply because human nature is difficult to be contained and dissected.

Keywords: Freud, Psychoanalysis, Yung, Lawrence, Literature, Lacan, Adler

It seems that attaining knowledge, particularly of natural phenomena, is the ultimate aim of science. The way to achieve that is usually through experimentation and evidence, although this is not always easy to realize, especially concerning large speculations related to the origin of life and the evolution of the universe. Science stands against superstitions and explains phenomena without resorting to the metaphysical world, simply because it is beyond material experimentation. Relying on human impulse, intuition, on the other hand, does not usually demand a solid proof. It is influenced by culture, upbringing and the whole environment. Given a suitable atmosphere, intuition may speculate in the right direction, and this with the help of experimentation may eventually lead to some sort of scientific theory.

The area between science and intuition is not as sharply defined as it looks, particularly in the field of human sciences like psychology, sociology, and anthropology. For example, Freudian theories of Oedipus complex, penis envy, Thanatos and others have been disputed by some prominent psychologists. Freud himself adjusted some of his views in the course of his long career. At times, one may suspect whether what one is dealing with is related to science or intuition. Moreover, even in the field of science, change is possible since life is developing and evolution has always been the law of nature.

Although literary writers before the establishment of psychoanalysis had been able to explore human nature psychologically, and many of them had penetrated human soul deeply, Freud was the first to try to systemize psychology. He inspired writers with a clearer picture of the human psyche and has dominated modern life with his theories.

The initial response to Freud's theories have always been shocking because the man was principally a scientist who ultimately depended on observation and experimentation and tried to come close to human nature as it is, regardless of the consequences. He was not concerned with any moral issues which he believed were the production of social circumstances and historical conventions. This does 


\section{Dr. Tarek Musleh}

not mean that whatever he says is true, because he is dealing with the human psyche, an area that is difficult to contain, and always open for further speculation and exploration. It is like a wave which cannot be halted and critically dissected. Naturally, Freud may have emphasized one aspect of human nature at the expense of another or others, but he remains a cultural force and a pioneering scientist in psychoanalysis, a field he himself has largely founded.

The main problem with some of his theories is his assumption of scientific objectivity and generalization when what he presents is in fact some kind of intuition and personal experience. Nobody denies the important role of sex in our life and development, but to claim that it is decisive in infants' development, which must result in the Oedipus complex and its negative consequences, is perhaps an exaggeration, to say the least. It may apply to some cases of unhealthy upbringing, but it is unlikely to apply to every human being. Similarly, Freud's theory of penis envy may be cultural as many feminists have concluded, rather than being intrinsic within every female. Perhaps it is not a question of lacking something as much as it is accepting the others objectively for whatever they are. Moreover, relating the penis to potency is perhaps cultural rather than anything else; that is why impotence among men is shameful, whereas women frigidity is not viewed that way. Thus, if there is difference in biology it does not necessitate either superiority or inferiority.

It is also possible that Freud establishes his theory of Thanatos by depending on the present conditions of life not, as he claims, on the basis that humans were nothing and yearn to become nothing again in a state of oblivion. Perhaps the human wars and disillusionment with all 'isms', in addition to their limitations and a self-centered human nature as we now know it, are all responsible for this rather hasty conclusion. It is quite possible in the future, though there is no sign so far in that direction, that things may change and human nature may respond accordingly.

As far as literature is concerned, Freud feels certain that writers are neurotic cases, and some sort of escapists, and can be psychoanalyzed through their material. However, the relationship between writer and work is not easy to determine, particularly by sophisticated writers who try to dramatize their material objectively, and consciously create an artistic distance between them and their characters. There is no question that there must be something of the artistic work in the creator; otherwise, why choosing this subject, and why in some cases the same pattern is repeated again in most of the writer's works! However, not even Freud can determine with absolute certainty whether this is the author's ego, or alter ego, or some kind of cultural element infiltrating in the psyche of either writer or character. More important still is the shift between enjoying the artistic quality of the work and only thinking of literary works as a field of psychoanalyzing writers.

D. H. Lawrence seems to me relevant here. He may be taken as an example of successful dramatization of some Freudian theories and of the problem of identifying writers with their work. Lawrence is a kind of intuitive idealist and has his own vision that human nature is not prone to dissection in the Freudian manner. He believes that individualism can never be contained, and that 'every individual is a fountain from the unknown.' In fact, Lawrence has written an article entitled 'A Non-Freudian Unconscious' in which he tries to refute the Oedipus complex by concluding that 'the incest motive is in its origin not a pristine impulse, but a logical extension of the existent idea of sex and love.' Ironically, Sons And Lovers which is seen as an autobiographical novel, dramatizes the negative influences of Oedipus complex and shows how the emotional life of the hero is crippled because of the dominant 'love' of his mother. In actual life, Lawrence had a relation with Jessie Chambers which was thwarted by his mother. Perhaps the case of Lawrence is unique here; he may himself have suffered from the Oedipus complex, simply because his own mother did not know how to handle the issue and bring him up in a healthy way; her domineering character and possessiveness took the better part of her. It is also possible that dramatizing his own past life artistically sorted out this problem for him, which means that literature may have a healing power, no matter how limited, on both writer and reader. It enables us to confront the problem that is buried in our unconscious. Women in Love is more complicated as a work of art. Although Birkin is a self-portrait of Lawrence himself, he is not always presented admirably. That is a sign of conscious writing, perhaps to hide a possible element of narcissism. Moreover, Gerald who is supposed to be a kind of villain, and represents at a conscious level the damaging influence of the machine and self-destructiveness, he is fully internalized; and perhaps Lawrence is drawn to him more than he would like to admit, as some critics have concluded. There is nothing wrong with psychoanalyzing writers on the basis of their work, but here the critic is not on solid ground to draw the right conclusion. 
Carl Jung, who was a follower of Freud, broke away with him because he thought the man lacked spirituality. Jung rejects the idea that literature is a pathological field of studying the neurosis of writers. He looks at writers' vision as not the product of a 'poetic mood' or 'rich fantasy', but is taken from 'primordial experience' transmitted through the 'collective unconscious', which is 'a certain psychological disposition shaped by the forces of heredity.' Myths in particular transmit certain archetypal images which appear again and again in great literature. Universal experiences of life, death, the seasons, etc. are constantly dramatized in literature.

Jacques Lacan establishes another challenge to Freudian universal validity. He insists that identity can only be constructed by interaction with others and is prone to change, in a 'relational' structure. Other people's opinions of us are of vital importance for our development, and even we become ourselves through the 'gaze' of 'the great other'. The 'other' stands for the whole society and in a world of globalization all humanity. Language, which is not our own making, is instrumental in shaping our identity. There is a direct connection between the repressive character of language and culture as they are crystallized in the term 'ideology' and the establishment of the conscious and unconscious life of individuals. Lack of freedom, social injustice, and unequal opportunities have all negative consequences on the individual, and are constantly buried in the human unconscious. Even literature has its own hold on us and we fall under its spell. It is interesting to note in passing that that is the reason why Brecht created conscious devices to draw us back to reality and become consciously critical of whatever is going on.

Other critics of Freud have emphasized other aspects, like Adler's interpretation of the inferiority complex as a motivation for prominence and superiority. In the world of psychology, although it is presumably a science, there will always be other voices in the future, either agreeing with or modifying the excesses of Freudianism, and perhaps responding to changes to crystallize different theories accordingly. The discipline is expected to continue fluctuating between science and intuition, simply because human nature is a mysterious world that can never be fully diagnosed.

\section{REFERENCES}

[1] Barthes, Roland. Trans. Stephen Heath. "The Death of the Author." The Norton Anthology of Theory and Criticism. Ed. Vincent B. Leitch. New York: W.W. Norton \& Company, 2001.

[2] Bowie, Malcolm. Psychoanalysis and the Future of Theory. Cambridge, MA: B. Blackwell, 1994.

[3] Ellmann, ed. Psychoanalytic Literary Criticism. ISBN 0-582-08347-8.

[4] Felman, Shoshana, ed. Literature and Psychoanalysis: The Question of Reading: Otherwise. ISBN 0-8018-2754-X.

[5] Frankland, Graham. Freud's Literary Culture. New York: Cambridge University Press, 2000.

[6] Freud, Sigmund. Trans. Alix Strachey. "The "Uncanny." The Norton Anthology of Theory and Criticism. Ed. Vincent B. Leitch. New York: W.W. Norton \& Company, 2001.

[7] Freud, Sigmund. Standard Edition of the Complete Psychological Works of Sigmund Freud. 24 Volumes. Trans and ed. James Strachey. London: Hogarth Press, 1953-74.

[8] Hertz, Neil. "Freud and the Sandman." The End of the Line: Essays on Psychoanalysis and the Sublime. Aurora, CO: The Davies Group, Publishers, 2009.

[9] Muller and Richardson, eds. The Purloined Poe: Lacan, Derrida and Psychoanalytic Reading. ISBN 0-8018-3293-4

[10] Rudnytsky, Peter L. \& Ellen Handler Spits, Eds. Freud and Forbidden Knowledge. New York: New York University Press, 1994.

[11] Smith, Joseph H. Ed. The Literary Freud: Mechanisms of Defense and the Poetic Will. New Haven, CT: Yale University Press, 1980.

\section{AUTHOR's BIOGRAPHY}

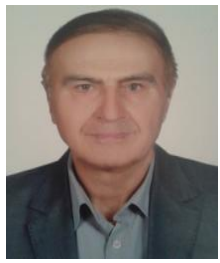

Dr. Tarek Musleh, is a Professor of English in the English Department of Jadara University, Jordan. He has published a number of papers mostly on fiction and a book titled: English Fiction from Defoe to Golding. Quite recently he has published a novelette and a collection of short stories by Just Fiction in Germany. 